\title{
Evaluating the Potential of Commercial Forest Inventory Data to Report on Forest Carbon Stock and Forest Carbon Stock Changes for REDD+ under the UNFCCC
}

\author{
Danae Maniatis, ${ }^{1,2}$ Yadvinder Malhi, ${ }^{1}$ Laurent Saint André, ${ }^{3,4}$ \\ Danilo Mollicone, ${ }^{2}$ Nicolas Barbier, ${ }^{5}$ Sassan Saatchi, ${ }^{6}$ Matieu Henry, $, 2,7,9$ \\ Laurent Tellier, ${ }^{10}$ Mathieu Schwartzenberg, ${ }^{11}$ and Lee White ${ }^{12}$ \\ ${ }^{1}$ School of Geography and the Environment, Environmental Change Institute, University of Oxford, Dyson Perrins Building, \\ South Parks Road, Oxford OX1 3QY, UK \\ ${ }^{2}$ Food and Agricultural Organisation of the United Nations, UN-REDD Programme, Viale delle Terme di Caracalla, \\ 00153 Rome, Italy \\ ${ }^{3}$ Inra, UR BEF, Biogéochimie des Ecosystèmes Forestiers, 54280 Champenoux, France \\ ${ }^{4}$ Cirad, UMR Ecoß́Sols, Ecologie Fonctionnelle \& Biogéochimie des Sols \& Agroécosystèmes \\ (Montpellier SupAgro-CIRAD-INRA-IRD), 34060 Montpellier, France \\ ${ }^{5}$ Botany and Computational Plant Architecture, UMR IRD-AMAP, 34398 Montpellier, France \\ ${ }^{6}$ Jet Propulsion Laboratory, California Institute of Technology, Pasadena, CA, USA \\ ${ }^{7}$ Laboratorio di Ecologia Forestale, Di.S.A.F.Ri, Facoltà di Agraria, Università degli Studi della Tuscia, Via Camillo de Lellis, snc, \\ 01100 Viterbo, Italy \\ ${ }^{8}$ GEEFT, AgroParisTech-ENGREF, 648 rue Jean-François Breton, BP 7355, 34086 Montpellier, France \\ ${ }^{9}$ Institut de Recherche pour le Développement (IRD), UMR EcoßSols, SupAgro, Bâtiment 12, 2 place Viala, 34060 Montpellier, \\ Cedex 1, France \\ ${ }^{10}$ Sylvafrica Ltda, BP 1888, Immeuble Océane, Carrefour Saoti, Quartier Haut Gué Gué, Libreville, Gabon \\ ${ }^{11}$ TEREA, Résidence Nkové, Bâtterie IV, BP 831, Libreville, Gabon \\ ${ }^{12}$ Agence Nationale des Parcs Nationaux, Présidence de la République, BP 20379, Libreville, Gabon
}

Correspondence should be addressed to Danae Maniatis, danae.maniatis@gmail.com

Received 8 July 2010; Accepted 18 January 2011

Academic Editor: Guofan Shao

Copyright ( 2011 Danae Maniatis et al. This is an open access article distributed under the Creative Commons Attribution License, which permits unrestricted use, distribution, and reproduction in any medium, provided the original work is properly cited.

In the context of the adoption at the 16th Conference of the Parties in 2010 on the REDD+ mitigation mechanism, it is important to obtain reliable data on the spatiotemporal variation of forest carbon stocks and changes (called Emission Factor, EF). A reoccurring debate in estimating EF for REDD+ is the use of existing field measurement data. We provide an assessment of the use of commercial logging inventory data and ecological data to estimate a conservative EF (REDD+ phase 2) or to report on EF following IPCC Guidance and Guidelines (REDD+ phase 3). The data presented originate from five logging companies dispersed over Gabon, totalling 2,240 plots of 0.3 hectares. We distinguish three Forest Types (FTs) in the dataset based on floristic conditions. Estimated mean aboveground biomass (AGB) in the FTs ranges from 312 to $333 \mathrm{Mgha}^{-1}$. A 5\% accuracy is reached with the number of plots put in place for the FTs and a low sampling uncertainty obtained ( \pm 10 to $13 \mathrm{Mg} \mathrm{ha}^{-1}$ ). The data could be used to estimate a conservative EF in REDD+ phase 2 and only partially to report on EF following tier 2 requirements for a phase 3.

\section{Introduction}

Emissions from deforestation and forest degradation are known to be important contributors to human induced climate change. During the 1990s, the combined effects of logging, clear-cutting, and forest regrowth on abandoned land are estimated to have released an amount equivalent to $10-25 \%$ of total annual anthropogenic emissions of 
$\mathrm{CO}_{2}$ [1-4]. Recent estimates are lower however; both as original methodologies have been revised and as the emissions from fossil fuel combustion have risen steeply, with the relative contribution of $\mathrm{CO}_{2}$ emissions from deforestation and forest degradation estimated at $12 \%$ of total annual anthropogenic emissions of $\mathrm{CO}_{2}$ for 2008 [5]. Nonetheless, deforestation is the second most important human induced source of $\mathrm{CO}_{2}$ to the atmosphere after fossil fuel combustion [5]. Under the Kyoto Protocol, reducing emissions from tropical deforestation and forest degradation (also known as REDD+) cannot be credited in the first commitment period (up to 2012).

Significant moves forward were made in developing REDD+ at the 15th and 16th Conference of Parties (COP) of the United Nations Framework Convention on Climate Change (UNFCCC) in Copenhagen in December 2009 and Cancun in December 2010, respectively. At COP 15 a Decision was adopted regarding "Methodological guidance for activities relating to reducing emissions from deforestation and forest degradation and the role of conservation, sustainable management of forests and enhancement of forest carbon stocks in developing countries" or REDD+ (Decision 4/CP.15). In December 2010, the 16th meeting of the COP resulted in a Decision including "Policy approaches and positive incentives on issues relating to reducing emissions from deforestation and forest degradation in developing countries; and the role of conservation, sustainable management of forests and enhancement of forest carbon stocks in developing countries" (Decision 1/CP.16 III C). Countries willing to participate in this REDD+ mitigation mechanism under the UNFCCC will have to establish a national forest monitoring system (Decision 4/CP.15 Paragraph 1(d)) that should support a Measurement, Reporting, and Verification (MRV) requirement under the Convention and a phase 3 of REDD+ which should be fully measured, reported, and verified under Decision 1/CP.16 III C.

Decision 4/CP.15 states that countries will have to use the most recent Guidance and Guidelines of the Intergovernmental Panel on Climate Change (IPCC), as adopted or encouraged by the COP, as a basis for estimating anthropogenic forest-related greenhouse gas (GHG) emissions by sources and removals by sinks, forest carbon stocks, and forest area changes (Decision 4/CP.15 Paragraph 1(c)). Estimating emissions and removals by sinks will have to be done in an adequate, consistent, complete, and transparent manner and be applied to the five carbon pools that will have to be measured and reported (these being aboveground biomass, belowground biomass, deadwood, litter, and soil organic matter) [6].

It is expected that REDD+ countries will have to provide estimates on forest carbon and forest carbon stock changes by 2012, when the Kyoto Protocol is expected to be replaced by the new agreement encompassing REDD+. 2012 is very close, and countries will be under pressure to provide the appropriate data in time if they wish to participate in the REDD+ mechanism.

A key task is the analysis of spatiotemporal variation of forest carbon stocks stored as vegetation biomass in tropical forests in line with the IPCC Guidance and Guidelines and the relevant COP Decisions on REDD+. Obtaining sufficient ground data to do so can be an expensive and timeconsuming undertaking. One of the recurring debates in measuring forest carbon stocks and forest carbon stock changes for REDD+ is the use of existing field measurement data. These mainly consist of data collected for scientific research purposes (ecological data), detailed but sparse in a given country, and commercial forest inventory data for logging purposes (inventory data) that cover large areas but are often less detailed for carbon studies. However, the latter might provide a basis for data acquisition and analysis on forest carbon stocks in REDD+ countries. Commercial forest inventory data have been used in several studies to estimate aboveground biomass (AGB) in tropical forests (e.g., [7-9]), yet to date they have not been evaluated in the context of REDD+ and reporting requirements under the UNFCCC.

In addition to the data that REDD+ participating countries need to produce or obtain to report for REDD+, there is a need for improved and more accurate methods of determining tropical forest biomass and understanding its spatial distribution. Most studies on AGB and carbon content have been conducted in the Brazilian Amazon and in SouthEast Asia, resulting in a considerable gap in knowledge and understanding of AGB patterns for sub-Saharan Africa. This is particularly the case for the Congo Basin Forest, the second largest tropical forest block in the world after the Amazon forest.

At the time of writing, the REDD+ context and methodological implications are still very new and in development. In this context, and following the IPCC Guidelines, the REDD+ COP Decisions and considering the gaps in AGB estimates for the Congo Basin Forest, the overarching goal of this paper is to identify the challenges in using commercial forest inventory data to report on forest carbon stock and forest carbon stock changes for REDD+. Our specific objectives are (i) to estimate one of the five carbon pools identified by the IPCC (AGB, frequently the largest pool) using existing commercial forest inventory data, (ii) to evaluate the estimated AGB in terms of precision, accuracy, and uncertainty, and (iii) to assess if this type of data could be used by countries to produce a conservative Emission Factor in phase 2 of a phased REDD+ and/or to report on Emission Factors following at least tier 2 requirements (see next) for a third REDD+ phase. The analysis will focus on data from Gabon as a case study in the Congo Basin Forest region.

\section{Study Framework}

2.1. Some Key Concepts regarding REDD+, $M R V$, and the $I P C C$. With regards to land use, and land use change and forestry (LULUCF), five forest-related activities have been identified in the REDD+ context (Decision 1/CP.16 III C): (i) deforestation, (ii) forest degradation, (iii) conservation, (iv) sustainable management of forests, and (v) enhancement of forest carbon stocks.

The simplest and most commonly used methodological approach to quantify emissions and removals for a national GHG inventory presented in the IPCC Good Practice Guidance [10] is the combination of (i) the extent to which human 


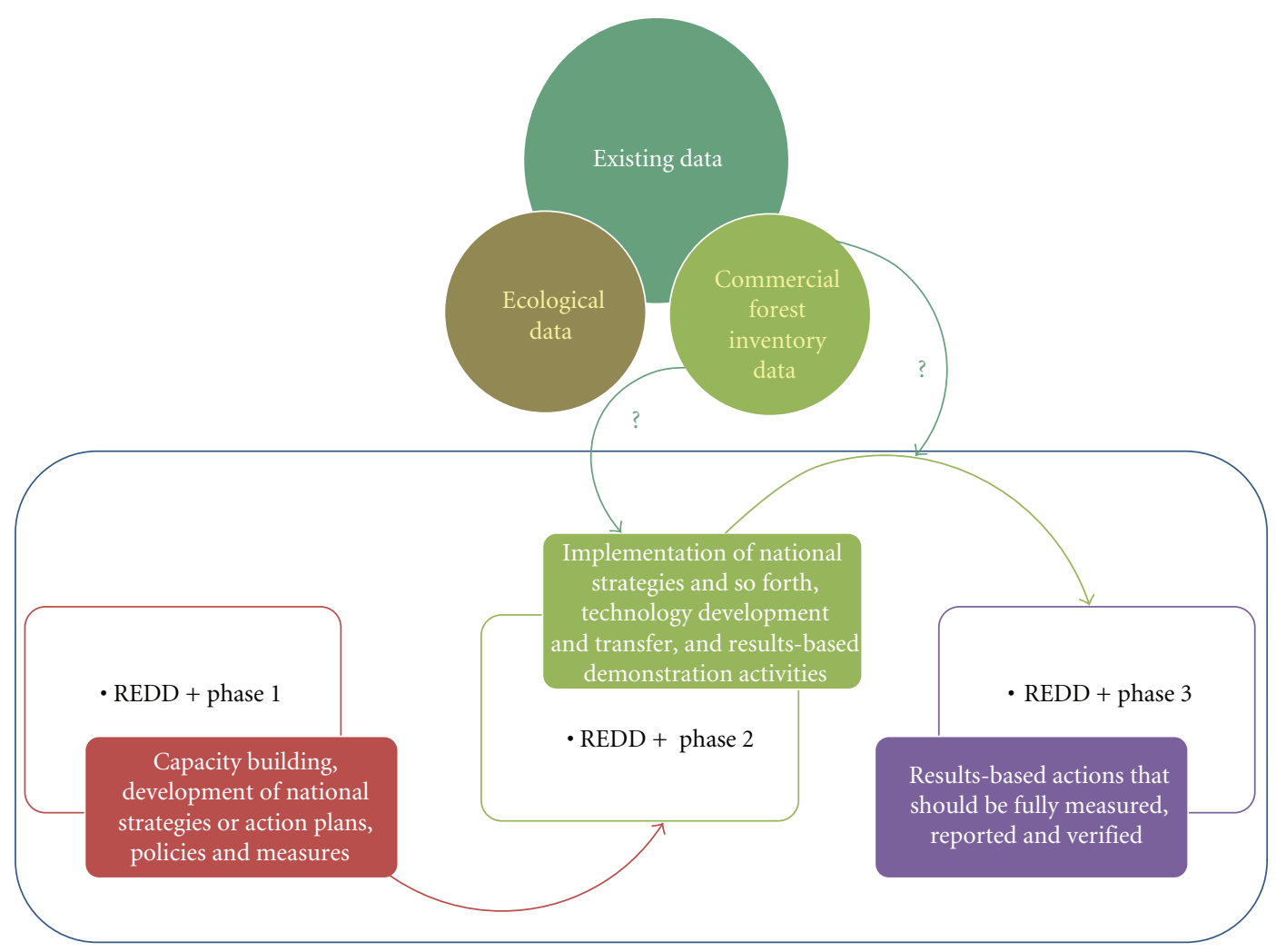

FIGURE 1: Diagrammatic representation of the existing data and its potential input in the REDD+ implementation process. The central question is if commercial forest inventory data could be used to provide the necessary information (i) to establish a conservative estimate on Emission Factor (EF) and (ii) to report on EF at a tier 2 level.

activities take place, which for REDD+ applies principally to forest area and forest area change (called activity data or AD) with (ii) coefficients that quantify the emissions or removals per unit activity, which for REDD+ applies principally to forest carbon stocks and forest carbon stock changes (called emission factors or EF). The basic equation is therefore

$$
\text { Emissions }=\mathrm{AD} \times \mathrm{EF} .
$$

A country will have to report on carbon stock changes (emissions and/or removals by sinks) only if these are human induced. In that respect the IPCC advises the use of the "managed land" concept as a proxy to discriminate human induced emissions. Only changes in managed land will have to be estimated and reported. The commercial forest inventory data are ideal in this sense, as they would be considered as "managed" land and cover important forest surfaces of many tropical forest countries.

Producing the national GHG inventory can be done at three different levels of accuracy and methodological complexity which are called "tiers." Tier 1 is the basic method and uses default values obtained from the IPCC Emission Factor Database; tier 2 is the intermediate and improves on tier 1 by using country-specific data; finally tier 3 is the most demanding in terms of complexity and data requirements. Tiers 2 and 3 are generally referred to as the "higher-tier" methods and are generally considered to be more accurate. It is considered good practice to apply the higher-tier methods to key categories, unless the resource requirements to do so are considered prohibitive [6]. Following the most recent IPCC guidelines $[6,10]$ and the REDD+ COP Decisions, the minimum objective of countries that wish to participate in a mitigation mechanism (such as REDD+) under the UNFCCC should be to compile a national GHG inventory with estimates of carbon stock changes with a known certainty and accuracy (tier 2 or tier 3 level).

In order to meet these criteria, a country will need to have (i) country-specific estimates of EF, including the five IPCC carbon pools, (ii) multitemporal inventory data, and (iii) uncertainty estimates with any data reported. The IPCC indicates that a quantitative uncertainty analysis should be performed by estimating the $95 \%$ Confidence Interval (CI) of the emissions and removals estimates for individual categories and for the total data collection method. Furthermore, it is good practice that estimates respect the "conservativeness principle," that is, when completeness or accuracy of estimates cannot be achieved, the reduction of emissions (for REDD+ based on forest carbon stock and forest carbon stock change estimates) should not be overestimated, or at least the risk of overestimation should be minimized [11]. For a brief overview of the IPCC's methodological approach in relation to REDD+ and forest inventories specifically, we refer to [12].

As indicated in the COP16 Decision (Decision 1/CP.16 III C Paragraph 73), REDD+ will be implemented in phases to 


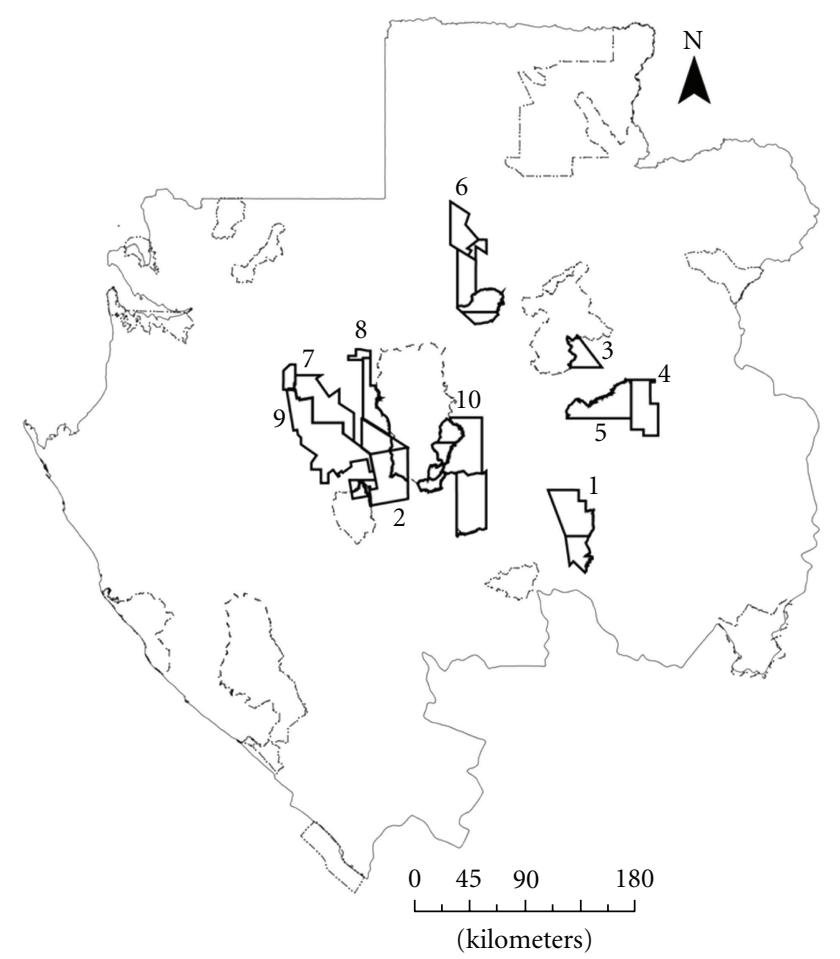

FIGURE 2: Distribution of logging concessions featuring in this study for Gabon. Dotted lines represent the boundaries of the national parks in the country.

allow countries to participate in the mechanism while taking account of their national circumstances. Most countries interested in REDD+ are currently in the first phase: the development of national strategies or action plans, policies and measures, and capacity building. Following this, two more phases will take place: (i) the implementation of national policies and measures and national strategies or action plans that could further involve capacity building, technology development and transfer and results-based demonstration activities and (ii) evolving into results-based actions that should be fully measured, reported, and verified (Figure 1). As stated previously, the third aim of this paper is to evaluate if and how commercial forest inventory data can be used to support any of these phases, especially the last two.

2.2. Logging Context in Central Africa and Gabon. The key factor driving forest fragmentation and degradation, and thus the key to near-term management of forests in Central Africa and in particular Gabon, is now commercial logging.

With a land area of approximately 26.8 million ha, Gabon is the least densely populated country in Central Africa with approximately 1.5 million inhabitants and an average of 5 persons per square kilometre [13]. Gabon's forests, which cover an estimated $77 \%$ of its land surface, contain over 400 species of tree, with approximately 100 species suitable for commercial purposes. Commercial exploitation began around 1882, and in 1913 Okoumé (Aucoumea klaineana Pierre), Gabon's most valuable wood, was introduced to the international market. Forestry was the primary source of economic income until about 1968 when the industry was supplanted by crude oil as a source of foreign exchange. Gabon's small population, combined with high revenues from oil production and high operating costs, has sheltered its forest resources from demographic, agricultural, and industrial pressures [14].

Gabon's tropical timber exports reached a peak of 1.9 million $\mathrm{m}^{3}$ in 2007 , declined to 1.8 million $\mathrm{m}^{3}$ in 2008 and increased slightly in 2009. It is now the largest exporter of tropical hardwood of the region, and it is the International Tropical Timber Organization's (ITTO) third largest exporter of tropical logs (unprocessed/raw logs). However, Gabon's log exports are expected to plummet in 2010 following the implementation of the log export ban [15].

\section{Methods}

3.1. Study Sites. The field measurement data presented here originates from five different logging companies operating in the central area of Gabon (Figure 2), totalling ten logging concessions. Each of the management inventories was undertaken by the same study bureau (Sylvafrica, Gabonhttp://www.onfinternational.org/en/onfi-abroad/sylvafric. .html). Hence the methodologies used across the concessions are as consistent as possible.

\subsection{Two Different Data Sets}

Dataset 1: Commercial Forest Inventory Data. The Gabonese Forestry Code (art. 56) requires commercial logging companies to undertake an "inventaire d'aménagement" or "management inventory." As part of this Management Inventory (MI), companies are required to assess the floristic composition and structure of the forest in their concessions, for all species. Article 58 of the Gabonese Forestry Law $16 / 01$ stipulates that the minimal level of accuracy required for a Forest Management Unit (FMU-Unité Forestière d'Aménagement (UFA)) equals $10 \%$ of the global number and volume of stems of the most important exploitable species at the time of the first rotation.

The inventory method used by Sylvafrica is based on a systematic inventory of 0.3 ha plots $(100 \mathrm{~m} \times 30 \mathrm{~m})$. Tree diameters are measured in the plots but not specifically noted. Rather, trees are placed in diameter windows of $5 \mathrm{~cm}$, where the middle diameter of the diameter class is assigned to the tree, for example, $20 \mathrm{~cm}$ for the window 17.5 to $22.5 \mathrm{~cm}$. Within the plots, three subdivisions are made. The first is a subplot of $0.075 \mathrm{ha}(25 \mathrm{~m} \times 30 \mathrm{~m}$; Sp 1) where all trees with a diameter at breast height $(\mathrm{DBH})$ above $17.5 \mathrm{~cm}$ are, in principle, measured. In the second subplot of 0.105 ha $(35 \mathrm{~m} \times 30 \mathrm{~m}$; Sp 2), all trees with a DBH above $37.5 \mathrm{~cm}$ are included and finally, in the third subplot of $0.12 \mathrm{ha}(40 \mathrm{~m}$ $\times 30 \mathrm{~m}$; Sp 3) all trees with a diameter above $57.5 \mathrm{~cm}$ are included (Figure 3). An example of such a layout is presented for concession 1 (Figure 4). Only commercial tree species are measured in the 5 ha transect, hence this data is not used in our analysis. 


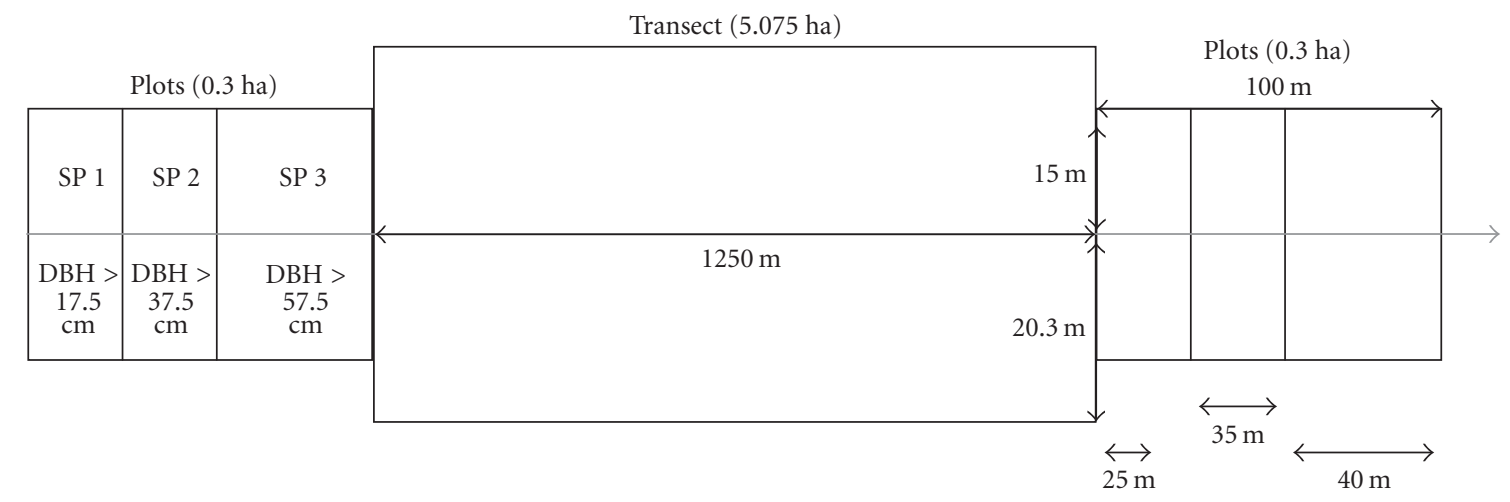

FIGURE 3: Schematic of sampling method (adapted from Sylvafrica-SP: subplot; DBH: diameter at breast height). Note that figure is not to scale. The plots of $0.3 \mathrm{ha}(100 \mathrm{~m} \times 30 \mathrm{~m})$ are separated by transects of $5.075 \mathrm{ha}$. Each plot is subdivided into three subplots. The first is a subplot of $0.075 \mathrm{ha}(25 \mathrm{~m} \times 30 \mathrm{~m})$ (SP 1). The second subplot is $0.105 \mathrm{ha}(35 \mathrm{~m} \times 30 \mathrm{~m})$, (SP 2). The third subplot is $0.12 \mathrm{ha}(40 \mathrm{~m} \times 30 \mathrm{~m})$.

Species were determined in the field using pilot names that were related to their scientific names using a database developed by Sylvafrica.

Dataset 2: Ecological Data. In order to evaluate the accuracy of AGB estimates and account for smaller diameter classes $(10-17.5 \mathrm{~cm})$ in the commercial inventory plots, we used and analysed 25 permanent "ecological plots". These are located in concession 9, have an area of 0.25 ha $(50 \mathrm{~m} \times$ $50 \mathrm{~m}$ ) and were measured in 2002. In contrast with the commercial forest inventory plots, no subplots were used in the permanent ecological plots. All trees above $10 \mathrm{~cm}$ were measured and species were identified carefully.

3.3. Classification of Forest Types. The data set extends over the dense forests of Gabon. The concession boundaries have been drawn based on administrative regulations and as such do not represent ecological zones and/or regions. Therefore, analysing the AGB of the forests by concession has little ecological relevance. In scaling up AGB estimates, it would be more useful to stratify the forests based on their floristic composition to provide more detailed information on the variability of its forest carbon stocks. Here we explore and demonstrate how such a stratification can be undertaken with commercial inventory data. To classify these forests into distinct forest types (FTs) using the percentage frequency/abundance for all families present in each plot, we applied agglomerative hierarchical clustering (AHC) using XLSTAT. The clustering analysis was done at the family level rather than at the species level to avoid uncertainties of species identification during the inventory. Depending on the objectives, using a clustering analysis based on extensive field data can provide a better representation of the forests than existing general stratifications or phytogeographical classifications.

An AHC analysis queries clusters without any previous understanding of the number of groups or their structure. For every iteration of the algorithm, the two nearest clusters are merged. AHC requires the definition of two elements which are (i) a measure to compute the distance between each pair of individuals and (ii) an agglomerative criterion that can be seen as a distance between two clusters. For the former we used Euclidean distance as a dissimilarity measure. For the latter we used Ward's method for agglomeration (which consists of fusing the two clusters that minimise the increase in the total within-clusters sum of squares). Different truncation levels were used, and finally three FTs were retained as lower truncation levels (using more FTs did not provide more ecological insight).

\subsection{Estimating Aboveground Biomass}

Step 1: Allometric Equation and Input Variables. To calculate the AGB of the plots, we used the allometric equation for "moist forest" stands provided by Chave et al. [16] including the Correction Factor for the back transformation from the $\log$-log to the exponential form (see (7) and Table 4 in [16]):

$$
\begin{aligned}
& \left\langle\mathrm{AGB}_{\text {est }}\right\rangle \\
& =\rho \exp \left(-1.562+2.148 \ln \mathrm{DBH}+0.207(\ln \mathrm{DBH})^{2}\right. \\
& \left.\quad-0.0281(\ln \mathrm{DBH})^{3}\right) \times \exp \left(\frac{\sigma^{2}}{2}\right)
\end{aligned}
$$

where $\sigma$ is $0.356, \rho$ is wood density in $\mathrm{g} \mathrm{m}^{-3}$, and DBH in centimetres. The AGB estimate is then in $\mathrm{kg}$, which is converted into $\mathrm{Mg} \mathrm{ha}^{-1}$.

Average wood density of the species present in the field inventories was found at species level or genus level, as genus level has been found to be representative of species-level wood density $[17,18]$ using the wood densities in the Global Wood Density Database [19] and wood densities derived by Maniatis et al. [18] for 248 species. For the other 83 species where no representative information could be found, the average value of the 248 species was used (in this case 0.624 with a standard deviation of $0.153 \mathrm{~g} \mathrm{~cm}^{-3}$ ).

Step 2: AGB Calculations for the Inventory Plots. To calculate the AGB per unit area for each 0.3 ha plot $(a)$ and all subplots 


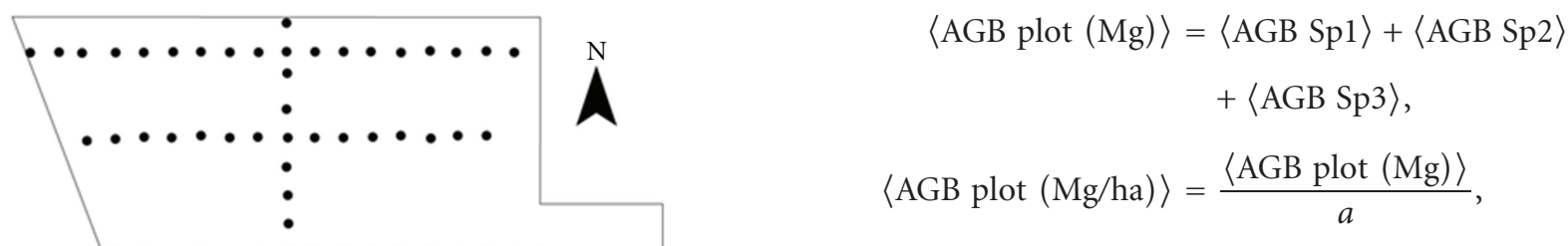

where $\mathrm{Sp}$ is the subplot, $a, a_{1}, a_{2}$, and $a_{3}$ are the areas for the plot, subplot 1,2 , and 3 , respectively. dclass1Sp1 is the biomass of all the trees that fall into diameter class 1 for subplot 1, dclass $2 \mathrm{Sp} 2$ for the trees that fall into diameter class 2 for subplot 2, and so forth. The diameter classes are as follows: dclass $1=17.5-<37.5 \mathrm{~cm}$ (assigned tree DBH ranges: $20-25-30-35 \mathrm{~cm}$ ); dclass $2=37.5-<57.5 \mathrm{~cm}$ (assigned tree DBH ranges: $40-45-50-55 \mathrm{~cm}$ ); dclass $3 \geq$ $57.5 \mathrm{~cm}$ (assigned tree DBH $60 \mathrm{~cm}$ and above). Note our distinction between three broad diameter classes (defined in the previous sentence) and the diameter windows of $20.0 \pm$ $2.5 \mathrm{~cm}, 25.0 \pm 2.5 \mathrm{~cm}$, and so forth.

Step 3: AGB Calculations for the Ecological Plots. The AGB for the ecological plots is calculated as described in Step 1.

Step 4: Evaluating Uncertainty on Tree-Level AGB Estimate. There are two main sources of error and uncertainty for the tree-level AGB estimate: (i) the measurement error $\left(\sigma_{\mathrm{M}}\right)$ and (ii) the uncertainty surrounding the choice of allometric equation $\left(\sigma_{\mathrm{A}}\right)[20]$. When scaling from a tree AGB estimate to a plot $\mathrm{AGB}$ estimate, the measurement error declines with increasing number of trees sampled. The allometric equation uncertainty, however, can either be a precision error (individual trees have a form differing from the mean tree form) that declines with increased tree sample size or a systematic (accuracy) error that persists independent of sampling size (the mean tree form in the study area is different from that assumed in the allometric equation). We assume that the measurement and the allometric uncertainties are independent sources of variability. Monte Carlo simulations were used to simulate the parameters to calculate $\sigma_{\mathrm{M}}$ and $\sigma_{\mathrm{A}}$ [21].

The errors in trunk diameter and density measurement all result in an error in estimating the AGB taken from an allometric model. We denote the standard error associated with the diameter measurement as $\sigma_{\mathrm{D}}$. We assume that the largest source of error here arises from the assignment of diameters into $5 \mathrm{~cm}$ windows, rather than any direct measurement error. As it was not possible to remeasure a subset of the trees, we took the "noted" diameter and assumed that the errors in diameter followed a centred normal distribution with a standard deviation of $2.5 \mathrm{~cm}$ (the error is assumed to be equal to the diameter windows).

Errors for wood density mainly arise from misidentification of the tree or a variation of wood density within or among conspecific trees [22]. In commercial forest inventories species are often determined approximately, and the use of pilot names may include several species. We used the individual tree wood densities and assumed that the errors in 
wood density followed a centred normal distribution with a standard deviation of $0.1 \mathrm{~g} \mathrm{~cm}^{-3}$.

5,000 trees randomly selected from three concessions from the original dataset were used for the simulation for $\sigma_{\mathrm{M}}$ using (2). For each tree, the error in diameter and wood density was simulated 1,000 times (assuming independent normal distribution of errors). In other words, we varied $\rho$ and DBH at random for each tree 1,000 times. Tree AGB was calculated with the simulated diameters and wood densities $(1,000$ values $)$. We also calculated the "original" AGB for each tree, in other words, the AGB of the tree using the original diameter and wood density value.

To evaluate the error in tree AGB resulting from the allometric equation, we varied only $\varepsilon$ (in (4)) assuming a centred normal distribution with a mean of 0 and a standard deviation of 0.356 (residual standard error of the equation, see Chave et al. [16]). The same trees and number of simulations $(1,000)$ were used as described above:

$$
\begin{aligned}
& \left\langle\mathrm{AGB}_{\text {est }}\right\rangle \\
& =\rho \times \exp \left(-1.562+2.148 \ln \mathrm{DBH}+0.207(\ln \mathrm{DBH})^{2}\right. \\
& \left.\quad-0.0281(\ln \mathrm{DBH})^{3}\right) \times \exp (\varepsilon) .
\end{aligned}
$$

Step 5: Estimating AGB between 10-17.5 cm. Not accounting for smaller diameters can considerably underestimate plot level AGB. To correct for this, we used the data of the 25 permanent plots in concession 9. Equation (2) was used to calculate AGB. Wood density was treated as explained above. We estimated the percentage of AGB in trees from $10 \mathrm{~cm}$ to $17.5 \mathrm{~cm}$ to total plot AGB in order to be able to correct for the missing diameters between $10 \mathrm{~cm}$ to $17.5 \mathrm{~cm}$ in the inventory data. We did not estimate AGB for trees smaller than $10 \mathrm{~cm}$. However, this could be done down to $2 \mathrm{~cm} \mathrm{DBH}$ using biomass expansion factors such as the ones developed, for example, by Henry et al. [23] .

Step 6: Estimate of Plot Level AGB. To calculate the plot level AGB we applied (i) (3) and (4), (ii) the simulations described in step 4 on all trees for all plots, and (iii) the correction factor for the missing diameter classes resulting from step 5 in all plots. Hence, plot level AGB was simulated 1,000 times for all 2,240 plots using (4) through a Monte Carlo approach in Matlab (by varying epsilon, $\rho$, and DBH simultaneously). We regard these values as the most representative of their "true" precision and accuracy and therefore report these values. We also compare these values with the original AGB plot calculation by applying (i) (2) and (3) without random errors and (ii) the correction factor resulting from step 5 on all plots.

3.5. Statistical Analyses. Even though one could expect a normal distribution of AGB given that the overall plot size is greater than 0.25 ha $[20,24]$, AGB estimates per FT did not pass the normality test (Shapiro-Wilk test with alpha at 0.05: FT1 $=0.989, P<.0001$; FT2 $=0.990, P<.000$; FT3 $=0.994, P<.002)$. Nonparametric tests (Kruskal-Wallis)

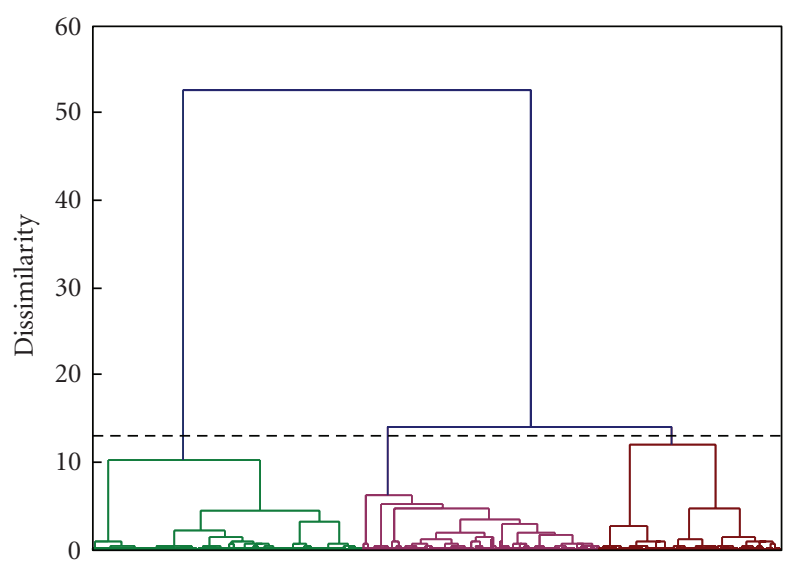

(a)

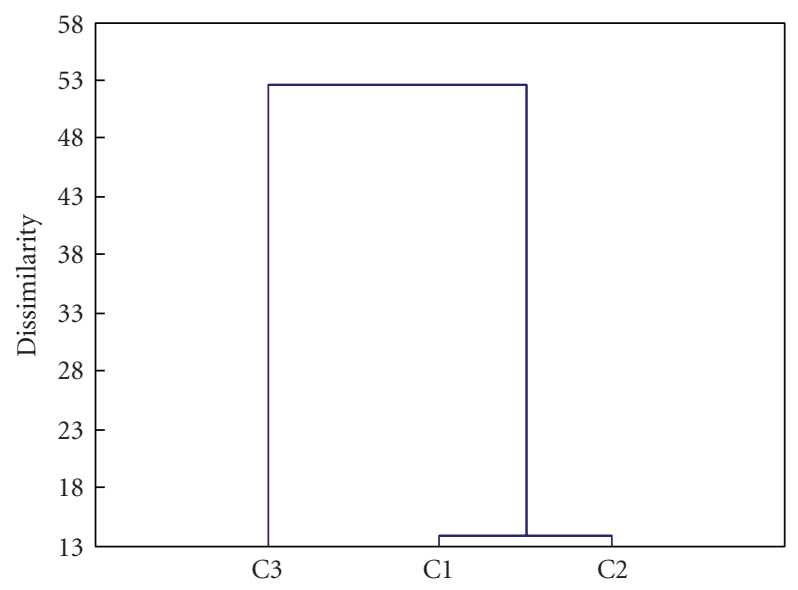

(b)

Figure 5: Results of the Agglomerative Hierarchical Clustering (AHC) analysis with Euclidean distance and Ward agglomeration resulting in three clusters $=$ three Forest Types $(\mathrm{FTs})$.

were used with a pairwise comparison to test relationships. Uncertainties are reported at 95\% Confidence Intervals.

The minimum number of sampling plots $(n)$ required to estimate AGB at a certain accuracy level for each of the concessions was calculated as follows [25]:

$$
n=\left(\frac{C \times t}{e}\right)^{2}
$$

where $C$ is the coefficient of variation, $e$ is the required accuracy, and $t$ is the Student's $t$ at the nominated probability level and the appropriate number of degrees of freedom (in this case $95 \%$; two-tailed $t=1.960$ ).

\section{Results}

4.1. Forest Types. Three FTs resulted from the agglomerative clustering analysis based on family abundance (Figure 5). Figure 6 shows how these are distributed over the concessions. The FTs can be described as follows using the 


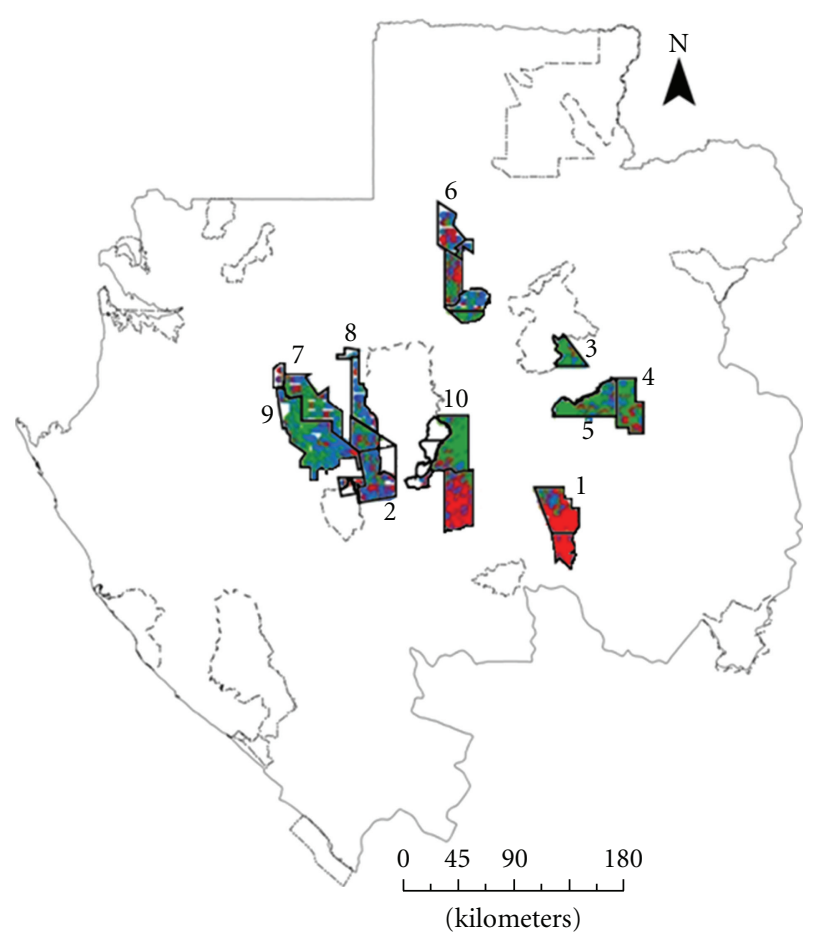

FIgURE 6: Distribution of the three FTs based on their floristic composition. Points represent 0.3 ha plots. FT1 are blue plots, FT 2 red plots, and FT3 green plots.

three botanical families that represent almost half of the population of trees with a $\mathrm{DBH}>17.5 \mathrm{~cm}$ :

(i) FT 1: 766 plots (blue plots in Figure 6) composed of Olacaceae (14\%), Caesalpiniaceae (14\%), Burseraceae $(13 \%)$;

(ii) FT 2: 589 plots (red plots) composed of Burseraceae (22\%), Myristicaceae (18\%), Euphorbiaceae (10\%);

(iii) FT 3: 885 plots (green plots) composed of Caesalpiniaceae $(40 \%)$, Burseraceae (10\%), Olacaceae (8\%).

FTs 1 and 3 are composed of the same families but with different relative proportions (Burseraceae, Caesalpiniaceae, and Olacaceae). FT 2 is composed of different families and different to the other two FTs. Caesalpiniaceae are indicative of primary and evergreen wet forest (Leal, pers. comm.; $[26,27])$, while Burseraceae are indicative of more open forest and perhaps degradation (Leal, pers. comm.).

In the dominant families in FT 1, the main species with relative proportions over $6 \%$ in the three dominant families are Santiria trimera (13\%), Coula edulis (11\%), Aucoumea klaineana (9\%), and Diogoa zenkeri (7\%)—-together comprising $40 \%$ of the species in the three families. FT 2 is largely dominated by Okoumé (Burseraceae) (24\% in itself of all species of the three dominant families) which is a pioneer species. The species with a relative abundance over $6 \%$ in the three dominant families of FT 3 are Santiria trimera $(8 \%)$, Scorodoploeus zenkeri (7\%), Julbernadia pellegriniana (7\%), and Dialium angolense (6\%)-together making up 29\% of the species in the three families. Based on the species that compose the dominant families, FT 3 is probably the least disturbed forest.

4.2. AGB Calculations. For the 25 permanent plots of 0.25 ha 2,836 trees were measured. These plots had an average AGB of $485 \pm 27 \mathrm{Mg} \mathrm{ha}^{-1}$ (note that, unless otherwise specified, with \pm in the text we denote the standard error). The average percentage of plot AGB in trees between $10 \mathrm{~cm}-17.5 \mathrm{~cm}$ to total plot AGB is $16 \pm 1 \mathrm{Mg} \mathrm{ha}^{-1}(4 \%)$. A correction of $4 \%$ of total plot AGB was applied to total plot AGB of the inventory plots to correct for these initially unaccounted small diameter classes.

For the commercial inventory plots, 2,240 plots of 0.3 ha were measured, totalling 675 ha and 48,310 trees (value not adjusted for missing diameter classes). These plots are distributed over a total area of $1,374,414$ ha spread across the country (Figure 1 ). We find that $\sigma_{\mathrm{M}}=0.68\langle\mathrm{AGB}\rangle$ and that $\sigma_{\mathrm{A}}=0.42\langle\mathrm{AGB}\rangle$. Therefore, the uncertainty of AGB estimation of a single tree is $110 \%$ of the estimated AGB, partitioned into $68 \%$ due to the measurement uncertainty and $42 \%$ due to the allometric model. At the stand level, the random aspect of measurement errors tends to cancel out, however. The precision of the allometry at the stand level is high; however the accuracy is lower. Furthermore, we observe that the simulated plot AGB is on average $3 \mathrm{Mg} \mathrm{ha}^{-1}$ (1\%) lower than the "original" plot AGB (i.e., the simulations are slightly biased by $1 \%$ ). We report the simulated AGB as they correct for the $5 \mathrm{~cm}$ diameter windows, uncertainties in wood density and the allometry and allow us to take the AGB variability better into account. The mean AGB for FTs 1,2 , and 3 are $333 \pm 7 \mathrm{Mg} \mathrm{ha}^{-1}, 312 \pm 7 \mathrm{Mg} \mathrm{ha}^{-1}$ and $324 \pm$ $5 \mathrm{Mg} \mathrm{ha}^{-1}$, respectively.

The mean "original" and "simulated" AGB per concession and FT, together with the mean of all plot AGB, are presented in Table 1 . No relationship was found between small tree AGB, medium tree AGB, and large tree AGB (AGB in diameter classes 1,2 , and 3 , resp.) in the commercial inventory plots.

There is a significant difference in AGB between FTs 1 and 2 and FTs 2 and $3(P<.05)$, reflecting the floristic composition of the FTs as described above. In terms of average wood density there is a difference between all the FTs $(P<.05)$. However, wood density is higher in FTs 1 and 3 than in FT 2 (Table 1), again reflecting the floristic composition of the forest. This difference is not observed for DBH (Table 1). The lower wood density could explain the lower AGB in FT 2.

Taking the diameters above $17.5 \mathrm{~cm}$ for both the permanent and commercial forest inventory plots in concession 9, on average, the total number of trees measured is slightly lower $(23 \%)$ in the inventory plots $\left(187 \pm 3\right.$ trees ha ${ }^{-1}$ adjusted per plot by adapting equation (3) to diameter instead of AGB) than in the permanent plots (243 \pm 2 trees ha $\left.{ }^{-1}\right)$. However, it appears that the range of the number of trees measured in the commercial forest inventories is much larger (9-443 trees $\mathrm{ha}^{-1}$ ) than in the ecological plots (164-328 trees ha $\left.{ }^{-1}\right)$. 
TABLE 1: Summary information for the concessions (C) and forest types (FTs). For all the plots, each of the logging concessions and for the three Forest Types (FTs): fully corrected aboveground biomass estimates (AGB Mg ha ${ }^{-1}$ ), mean wood density $\left(\mathrm{WD} \mathrm{g} \mathrm{cm}^{-3}\right)$, and mean DBH $(\mathrm{cm})$. Uncertainty values indicate respective standard errors of the mean.

\begin{tabular}{|c|c|c|c|c|c|c|}
\hline & $\begin{array}{l}\text { Number of } \\
\text { plots }\end{array}$ & $\begin{array}{c}\text { Total area } \\
\text { measured } \\
\text { (ha) }\end{array}$ & $\begin{array}{c}\text { Mean AGB } \\
\left(\mathrm{Mgha}^{-1}\right)\end{array}$ & $\begin{array}{l}\text { Simulated mean } \\
\text { AGB }\left(\mathrm{Mg} \mathrm{ha}^{-1}\right)\end{array}$ & $\begin{array}{l}\text { Mean WD } \\
\left(\mathrm{g} \mathrm{cm}^{-3}\right)\end{array}$ & $\begin{array}{l}\text { Mean DBH } \\
\quad(\mathrm{cm})\end{array}$ \\
\hline All plots & 2240 & 672 & $327 \pm 3$ & $324 \pm 3$ & $0.635 \pm 0.001$ & 46 \\
\hline $\mathrm{C} 1$ & 217 & 65.10 & $345 \pm 10$ & $339 \pm 12$ & $0.576 \pm 0.003$ & 46 \\
\hline $\mathrm{C} 2$ & 257 & 77.10 & $322 \pm 7$ & $318 \pm 10$ & $0.640 \pm 0.003$ & 43 \\
\hline C 3 & 70 & 21.00 & $347 \pm 18$ & $345 \pm 23$ & $0.651 \pm 0.005$ & 46 \\
\hline C 4 & 147 & 44.10 & $341 \pm 11$ & $337 \pm 14$ & $0.642 \pm 0.005$ & 47 \\
\hline C 5 & 147 & 44.10 & $351 \pm 10$ & $348 \pm 14$ & $0.642 \pm 0.004$ & 47 \\
\hline C 6 & 178 & 53.40 & $363 \pm 10$ & $359 \pm 13$ & $0.638 \pm 0.003$ & 45 \\
\hline C 7 & 164 & 49.20 & $250 \pm 8$ & $248 \pm 10$ & $0.663 \pm 0.004$ & 43 \\
\hline C 8 & 70 & 21.00 & $379 \pm 15$ & $376 \pm 21$ & $0.651 \pm 0.005$ & 45 \\
\hline C 9 & 578 & 173.4 & $302 \pm 5$ & $299 \pm 6$ & $0.612 \pm 0.003$ & 44 \\
\hline C 10 & 412 & 123.6 & $342 \pm 6$ & $342 \pm 8$ & $0.674 \pm 0.002$ & 48 \\
\hline FT 1 & 766 & 229.8 & $335 \pm 5$ & $333 \pm 7$ & $0.646 \pm 0.002$ & 45 \\
\hline FT 2 & 589 & 176.7 & $315 \pm 5$ & $312 \pm 7$ & $0.579 \pm 0.002$ & 45 \\
\hline FT 3 & 885 & 265.5 & $327 \pm 4$ & $324 \pm 5$ & $0.664 \pm 0.001$ & 46 \\
\hline
\end{tabular}

TABLE 2: Number of plots required for a specified accuracy level for fully corrected simulated aboveground biomass $\left(\mathrm{Mg} \mathrm{ha}^{-1}\right)$.

\begin{tabular}{lccc}
\hline & \multicolumn{3}{c}{ Number of plots for required accuracy level } \\
& $5 \%$ accuracy & $10 \%$ accuracy & Existing plots \\
\hline All plots & 408 & 102 & 2,240 \\
1 & 448 & 112 & 217 \\
2 & 354 & 89 & 267 \\
3 & 480 & 120 & 70 \\
4 & 411 & 103 & 147 \\
5 & 343 & 86 & 147 \\
6 & 367 & 92 & 178 \\
7 & 440 & 110 & 164 \\
8 & 320 & 80 & 70 \\
9 & 399 & 100 & 578 \\
10 & 374 & 94 & 412 \\
FT 1 & 476 & 119 & 766 \\
FT 2 & 407 & 102 & 589 \\
FT 3 & 343 & 86 & 885 \\
\hline
\end{tabular}

TABLE 3: Fully corrected and simulated mean aboveground biomass $\left(\mathrm{Mg} \mathrm{ha}^{-1}\right)$ for each forest type with 95\% Confidence Intervals (CIs).

\begin{tabular}{lc}
\hline Type & Mean AGB \pm CI \\
\hline All plots & $324 \pm 7$ \\
FT 1 & $333 \pm 13$ \\
FT 2 & $312 \pm 13$ \\
FT 3 & $324 \pm 10$ \\
\hline
\end{tabular}

4.3. Accuracy and Uncertainty. The number of plots that have been put in place for each concession is systematically higher than that requested to attain a $10 \%$ accuracy level, and in some cases even a $5 \%$ level (Table 2). The numbers of plots put in place for the FTs are all higher than requested to attain than the $5 \%$ accuracy level. The uncertainty of the AGB in total and per FT is low (Table 3).

\section{Discussion}

5.1. Data Challenges for Emission Factors for REDD+. Our analyses show that commercial forest inventories are potentially useful for the estimation of the AGB forest carbon stock pool. However, we have shown that a number of factors limit their utility. The main practical challenges for a country to use these data to (i) produce conservative EF estimates for a phase 2 implementation of REDD+ and (ii) to report at a tier 2 on $\mathrm{EF}$ for phase 3 are the following.

(1) A "formal" agreement between a government and the logging companies/study bureaus will have to be established for handover of the data.

(2) The data will need to be in their "raw format" so they can be adequately analysed.

(3) If different field methodologies have been used these will have to be harmonized and standardised.

(4) Smaller trees (e.g., at least up to a lower limit of $10 \mathrm{~cm} \mathrm{DBH}$ ) need to be measured. If not, a suitable correction will need to be applied.

(5) In many commercial forest inventories, the diameter is measured but not noted, and instead trees are placed in diameter classes (e.g., of $5 \mathrm{~cm}$ ).

(6) The data provide information on one carbon pool only (AGB). 
(7) Information on forest carbon stock changes over time is lacking.

(8) Plots are usually not permanent and not tagged making it difficult to revisit plots for additional measurements either to improve the estimates or to measure a carbon stock change after logging activities.

(9) A country will have to report on its entire managed forest land, meaning on its different forest types. Commercial forest inventory data often only cover dense forests. Countries will still have to report other forest types and hence find or produce data on such other forests.

5.2. Forests and $A G B$. Forest stratification affects the values a country could report on of forest carbon stock and forest carbon stock changes. Many forest stratifications are coarse and often largely based on remote sensing data and analysis. We have shown that, with this dataset, it is possible to propose a forest stratification that reflects the floristic composition of the forest and can reflect forest ecology (e.g., FT 2 is indicative of a disturbed forest and is dominated by the pioneer species Okoumé). As they cover vast percentages of many countries' forest land, commercial forest inventory field data can be used to improve existing forest stratification maps [28-30] so that in the future they may be used as the basis for a more robust forest stratification to estimate forest carbon stock and carbon stock changes.

In our case study of Gabon, we estimated uncertainties introduced by omitting small trees, by using $5 \mathrm{~cm}$ diameter window, by misidentification and through its effects on wood density and by variations in the allometry. We find that the inventory AGB estimates presented (324 $\mathrm{Mg} \mathrm{ha}^{-1}$ ) fall within the upper range of studies that have been previously conducted for sub-Saharan tropical African forests ([8]: $164 \mathrm{Mg} \mathrm{ha}^{-1}$; [31] specifically for Gabon: $375 \mathrm{Mg} \mathrm{ha}^{-1}$, [32]: $\left.198 \mathrm{Mgha}^{-1}\right)$. The AGB estimates in the ecological plots appear to be high $\left(485 \mathrm{Mgha}^{-1}\right)$ compared to the other estimates.

Regarding the accuracy of the AGB estimates between the inventory plots and the ecological plots, we note that AGB in the ecological plots is higher $\left(485 \mathrm{Mg} \mathrm{ha}^{-1}\right)$ than in the inventory plots $\left(324 \mathrm{Mg} \mathrm{ha}^{-1}\right)$. This could be a result of two factors: (i) the implementation of the measurement method used by Sylvafrica (set up in this manner for very different purposes indeed) and (ii) the fact that the "ecological" plots we used for the analysis were consciously placed in "undisturbed primary" forest (with a distance rule of being at least $100 \mathrm{~m}$ to $150 \mathrm{~m}$ from roads) and may have a "majestic forest bias" in plot location. The former are assigned GPS coordinates in the office which the field teams are guided by for the actual field measurements. Measuring plots which are on steep slopes, rocky surfaces, near rivers, and so forth can result in a lower plot biomass and fewer trees measured. In order to really evaluate the accuracy of the differences in AGB values, the number of trees measured in different diameter ranges, and their effect on AGB, some "pseudo-" ecological plots would need to be randomly distributed over a large area, without targeting a specific forest type.

Comparing the number of trees measured in the permanent plots to the inventory plots for the same concession (concession 9), the number of trees recorded in the inventory plots appears to be $23 \%$ less than the number recorded in the ecological plots on a per-hectare basis. These are mainly in the smaller diameter classes, although a few big trees could also make the difference. This could be due to two factors. First, during the measurements in the inventory plots, some trees may have been missed during the measurements (in addition to those not measured in the last two diameter windows). Second, the difference could simply be due to landscape/vegetation differences as is the case for biomass.

As with many forest inventories, the diameter of the trees is not explicitly measured and noted, rather, only the diameter window is noted. If one assumes that the diameter distribution is exponential, taking the centre of the diameter window instead of the mean diameter in the window could result in a systematic overestimation of $\mathrm{AGB}[33,34]$, the latter reporting a $3 \%$ overestimation.

Due to the large number of plots that are put in place for commercial field inventory data, the accuracy of the AGB estimates appears to be better than 5\% for all FTs. Similarly, the sampling uncertainty associated with the data is low.

We observed that average wood density was significantly different for each of the FTs, with a higher wood density for FTs 1 and 3 (which are more indicative of a primary forest) than FT 2 (which is indicative of a more open and/or degraded forest), also resulting in a lower AGB in FT 2. Although a full ecological analysis is beyond the scope and purpose of this paper, this result merits some attention as it could suggest that wood density of the FTs is influenced by environmental variables and/or could reflect historic land use activities and changes. A more detailed ecological study is underway to test for relationships between wood density and variables such as soil type and historic land use in the Congo Basin Forest [34].

5.3. What Is Possible or Necessary to Use Inventory Data for $R E D D+$ ? The main limitation to respond to tier 2 requirements for a third phase of REDD+ using commercial forest inventory data does not seem to be country-specific data or accuracy (remember the three requirements listed in Section 2.1)-rather, it is the lack of multitemporal inventory data and data on forest carbon stock changes that present the biggest challenge. Multi-temporal data has two main purposes: first to provide information on forest carbon stock changes due to anthropogenic activities and second to study forest dynamics. Quantifying forest carbon stock changes due to logging activities is important information for an REDD+ country to report on EF. In this respect, a formal collaboration with logging companies to measure forest carbon stock changes (for all relevant carbon pools) in the field would provide valuable data for carbon stock and carbon stock change estimates due to logging and different logging practices. In theory, one option would be that if a same concession has previously been logged and the previous field inventory can be found, a comparison of the two 
forest carbon stocks in the same concession could provide a forest carbon stock change estimate or at least a preliminary assessment. In practice, unfortunately, the obligations for management inventories in Central Africa are recent, and it is questionable if this could be done.

Another challenge to respond to tier 2 requirements for a phase 3 is to obtain estimates for EF for the five carbon pools, of which AGB only represents one. To be able to provide conservative EF estimates for the second REDD+ phase, a country could use already established equations to estimate the carbon in the other four pools based on AGB. For example, allometric equations are often used to calculate the belowground biomass as a proportion of the aboveground biomass [35]. However, in order to respond to tier 2 requirements and/or a phase 3, countries would have to produce data to calculate a dynamic EF for AGB and the other four carbon pools with associated known uncertainties and accuracies.

The essence of the above is that, by knowing the error, accuracy, and uncertainty related to the AGB estimates, a country can make an informed decision on how conservative the values for forest carbon stocks will be that they report to the UNFCCC Secretariat for REDD+. Based on this data only, Gabon could, for phase 3, put forward a value of $324 \mathrm{Mg} \mathrm{ha}^{-1}$ for the forest carbon stock in the AGB carbon pool in its dense forests with a 5\% accuracy. For a second REDD+ phase, Gabon could use a general value of $324 \mathrm{Mg} \mathrm{ha}^{-1}$ for its forests. In this phase, it is optional for the country to include accuracy and uncertainty estimates for EF. However, we suggest that it is good practice to do so when and where possible. This would allow the country to be conservative and accurate in this second phase using existing and readily available data, whilst giving itself the opportunity to improve these data, collect additional data to fill the gaps, and fully prepare the country for the third phase which will be reported and verified.

\section{Conclusion}

Reliable AGB estimates for Central African and Gabonese forests that reflect the heterogeneity of the landscape are generally scarce. Tropical forest countries that wish to participate in a mitigation mechanism such as REDD+ will have to provide data in the near future $(\sim 2012)$ on forest carbon stocks and forest carbon stock changes while following IPCC Guidelines and the relevant REDD+ COP Decisions. In this context, we set out three specific objectives in the introduction of this paper.

The first one was to estimate AGB using existing commercial forest inventory data. We found that the fully corrected mean AGB in the FTs ranges from $312 \mathrm{Mg} \mathrm{ha}^{-1}$ to $333 \mathrm{Mg} \mathrm{ha}^{-1}$ in Gabon.

Secondly, we evaluated the estimated corrected AGB in terms of accuracy and uncertainty. We demonstrate that although the variability in AGB estimates is high, due to the large number of plots in each FT, the estimates for the FTs and almost all concessions have $10 \%$ accuracy and a low uncertainty ( \pm 10 to $13 \mathrm{Mgha}^{-1}$ ).
Finally, we questioned whether the data could be used to report on EF at a tier 2 level (phase 3) and/or to estimate a conservative emission factor in phase 2 of a phased REDD+ implementation. We find that the data could be used to produce a very conservative EF estimate for a second REDD+ phase. If one was more confident about the accuracy of the AGB values and forest carbon stocks, this data could partially respond to tier 2 requirements for a phase 3 .

It is evident from our analysis that several potential REDD+ countries will face data quality and quantity challenges to report on EF for the MRV-able phase 3. On one hand, available "ecological data" might be both precise and accurate but can often not be regarded as representative of the forest types. On the other hand, inventory data may be less precise and less accurate, but can be considered as representative of the forest types. Either way, our analysis has shown some of the major caveats of using commercial forest inventory data and/or ecological data to estimate AGB to report on EF following tier 2 requirements for phase 3 of REDD+. Subsequently, it may be desirable and in the medium term more cost-effective for certain REDD+ countries to undertake targeted fieldwork to produce specific data on EF to report to the UNFCCC Secretariat (cf. [12]). With less than one year to go before 2012, REDD+ countries will have to evaluate and decide soon what the best approach is for them to be able to report on EF following tier 2 requirements. If they decide to collect additional data and/or implement national forestry inventories specifically for this aim, the key questions will be as follows: (i) what resources are available; (ii) what in-country capacity is available to do so; (iii) how much time will be needed; (iv) as a result of that, what data compromises will have to be made for what phases.

The issues addressed in this paper also require some thought on how the scientific community could contribute towards optimizing existing data for REDD+ and how to help produce data in the appropriate format. In a first instance, there is a need for capacity building within this community to understand IPCC reporting requirements for REDD+ and how it may contribute to help REDD+ countries overcome these challenges. The scientific community could also provide tools to, for example, create a system to homogenise estimates between different commercial forest inventories, create decision tree rules to choose the most appropriate allometric equations and understand gaps and target methodological development to help REDD+ countries reach tier 2 reporting requirements for the MRV-able third phase of REDD+.

In conclusion, we believe that our analysis has illustrated the opportunities and challenges to use commercial forest inventory data to report on EF in an REDD+ context under the UNFCCC and the urgency of acquiring suitable data in a suitable format.

\section{Acknowledgments}

The authors thank anonymous reviewers for the useful and constructive comments that were provided. They thank Gil Lizcano and Przemyslaw Zelazowski for help with the initial programming that was needed for this analysis. They 
thank the following logging companies for contributing their management inventory data to this study: CFA/DLH, Cora Wood Gabon, Leroy Gabon, Rimbunan Hijau and SFIK (Société Forestière et Industrielle de Koulamoutou). The authors also thank WWF-UK for providing financial support for the original scoping study for forest inventory data in Gabon, the Packard Foundation, and the Gordon and Betty Moore Foundation for supporting this project. They thank Etienne Massard for supporting this research and Joel Scriven for proofreading the final paper. The views expressed in this publication are those of the author(s) and do not necessarily reflect the views of the Food and Agriculture Organization of the United Nations.

\section{References}

[1] R. A. Houghton, "Aboveground forest biomass and the global carbon balance," Global Change Biology, vol. 11, no. 6, pp. 945958, 2005.

[2] F. Achard, H. D. Eva, H. J. Stibig et al., "Determination of deforestation rates of the world's humid tropical forests," Science, vol. 297, no. 5583, pp. 999-1002, 2002.

[3] R. S. DeFries, R. A. Houghton, M. C. Hansen, C. B. Field, D. Skole, and J. Townshend, "Carbon emissions from tropical deforestation and regrowth based on satellite observations for the 1980s and 1990s," Proceedings of the National Academy of Sciences of the United States of America, vol. 99, no. 22, pp. 14256-14261, 2002.

[4] R. E. Gullison, P. C. Frumhoff, J. G. Canadell et al., "Tropical forests and climate policy," Science, vol. 316, no. 5827, pp. 985986, 2007.

[5] G. R. van der Werf, D. C. Morton, R. S. Defries et al., " $\mathrm{CO}_{2}$ emissions from forest loss," Nature Geoscience, vol. 2, no. 11, pp. 737-738, 2009.

[6] IPCC, "Good Practice Guidance for Land Use, Land-Use Change and Forestry," Institute for Global Environmental Strategies, Japan, 2003.

[7] S. Brown, A. J. R. Gillespie, and A. E. Lugo, "Biomass estimation methods for tropical forests with applications to forest inventory data," Forest Science, vol. 35, no. 4, pp. 881-902, 1989.

[8] G. Gaston, S. Brown, M. Lorenzini, and K. D. Singh, "State and change in carbon pools in the forests of tropical Africa," Global Change Biology, vol. 4, no. 1, pp. 97-114, 1998.

[9] T. R. Feldpausch, A. J. McDonald, C. A. M. Passos, J. Lehmann, and S. J. Riha, "Biomass, harvestable area, and forest structure estimated from commercial timber inventories and remotely sensed imagery in southern Amazonia," Forest Ecology and Management, vol. 233, no. 1, pp. 121-132, 2006.

[10] IPCC, "Guidelines for National Greenhouse Gas InventoriesVolume 4: Agriculture, Forestry and other Land Use," Institute for Global Environmental Strategies, Japan, 2006.

[11] G. Grassi, S. Monni, S. Federici, F. Achard, and D. Mollicone, "Applying the conservativeness principle to REDD to deal with the uncertainties of the estimates," Environmental Research Letters, vol. 3, no. 3, Article ID 035005, 2008.

[12] D. Maniatis and D. Mollicone, "Options for sampling and stratification for national forest inventories to implement REDD+ under the UNFCCC," Carbon Balance and Management, vol. 5, p. 9, 2010.
[13] CIA World Factbook, Gabon, Central Intelligence Agency, Washington, DC, USA, 2008, https://www.cia.gov/library/ publications/the-world-factbook/geos/gb.html.

[14] J. G. Collomb, J. B. Mikissa, S. Minnemeyer Mudunga et al., A First Look at Logging in Gabon. Global Forest Watch, World Resources Institute, Washington, DC, USA, 2000.

[15] ITTO, "Annual review and assessment of the world timber situation," Document GI-7/09. International Tropical Timber Organization. Yokohama, Japan. Prepared by the Division of Economic Information and Market Intelligence, ITTO, 2009.

[16] J. Chave, C. Andalo, S. Brown et al., "Tree allometry and improved estimation of carbon stocks and balance in tropical forests," Oecologia, vol. 145, no. 1, pp. 87-99, 2005.

[17] T. R. Baker, O. L. Philips, Y. Malhi et al., "Variation in wood density determines spatial patterns in Amazonian forest plots," Global Change Biology, vol. 10, pp. 1-18, 2004.

[18] D. Maniatis, L. Saint-André, M. Temmerman, Y. Malhi, and H. Beeckman, "The potential of using xylarium wood samples for wood density calculations: a comparison of approaches for volume measurements and preliminary ecological results," unpublished data.

[19] A. E. Zanne, G. Lopez-Gonzalez, D. A. Coomes et al., "Global wood density database," Dryad. Identifier, http://hdl. handle.net/10255/dryad.235.

[20] J. Chave, R. Condit, S. Aguilar, A. Hernandez, S. Lao, and R. Perez, "Error propagation and sealing for tropical forest biomass estimates," Philosophical Transactions of the Royal Society B, vol. 359, no. 1443, pp. 409-420, 2004.

[21] C. Sicard, L. Saint-Andre, D. Gelhaye, and J. Ranger, "Effect of initial fertilisation on biomass and nutrient content of Norway spruce and Douglas-fir plantations at the same site," Trees, vol. 20, no. 2, pp. 229-246, 2006.

[22] M. C. Wiemann and G. B. Williamson, "Geographic variation in wood specific gravity: effects of latitude, temperature, and precipitation," Wood and Fiber Science, vol. 34, no. 1, pp. 96107, 2002.

[23] M. Henry, C. Couralet, H. Beeckman et al., "Volume and biomass conversion factors for tropical rainforest and agroforestry systems in Africa," unpublished data.

[24] J. Chave, R. Condit, S. Lao, J. P. Caspersen, R. B. Foster, and S. P. Hubbell, "Spatial and temporal variation of biomass in a tropical forest: results from a large census plot in Panama," Journal of Ecology, vol. 91, no. 2, pp. 240-252, 2003.

[25] B. Zeide, "Plot size optimization," Forest Science, vol. 26, pp. 251-257, 1980.

[26] T. B. Hart, "Monospecific dominance in tropical rain forests," Trends in Ecology and Evolution, vol. 5, no. 1, pp. 6-11, 1990.

[27] J. Maley, "The African rain forest vegetation and palaeoenvironments during late quaternary," Climatic Change, vol. 19, no. 1-2, pp. 79-98, 1991.

[28] M. D. F. Udvardy, "A classification of the biogeographical provinces of the world," Morges (Switzerland): International Union of Conservation of Nature and Natural Resources. IUCN Occasional Paper no. 18, 1975.

[29] G. Caballe, "Essai phytogéographique sur la foret dense du Gabon," Annales de l'Université Nationale du Gabon, no. 02, pp. 87-101, 1978.

[30] D. M. Olson, E. Dinerstein, E. D. Wikramanayake et al., "Terrestrial ecoregions of the world: a new map of life on Earth," BioScience, vol. 51, no. 11, pp. 933-938, 2001.

[31] S. Brown and G. Gaston, "Use of forest inventories and geographic information systems to estimate biomass density of tropical forests: application to tropical Africa," Environmental Monitoring and Assessment, vol. 38, no. 2-3, pp. 157-168, 1995. 
[32] H. K. Gibbs and S. Brown, "Geographical Distribution of Woody Biomass Carbon in Tropical Africa: An Updated Database for 2000, NDP-055b," Carbon Dioxide Information Center, Oak Ridge National Laboratory, Oak Ridge, Tenn, USA, 2007, http://cdiac.ornl.gov/epubs/ndp/ndp055/ ndp055b.html.

[33] M. Keller, M. Palace, and G. Hurtt, "Biomass estimation in the Tapajos National Forest, Brazil examination of sampling and allometric uncertainties," Forest Ecology and Management, vol. 154, no. 3, pp. 371-382, 2001.

[34] S. Gourlet-Fleury, V. Rossi, M. Rejou-Mechain, V. Freycon et al., "Environmental filtering of dense-wooded species controls above-ground biomass stored in African moist forests," Journal of Ecology.

[35] M. A. Cairns, S. Brown, E. H. Helmer, and G. A. Baumgardner, "Root biomass allocation in the world's upland forests," Oecologia, vol. 111, no. 1, pp. 1-11, 1997. 

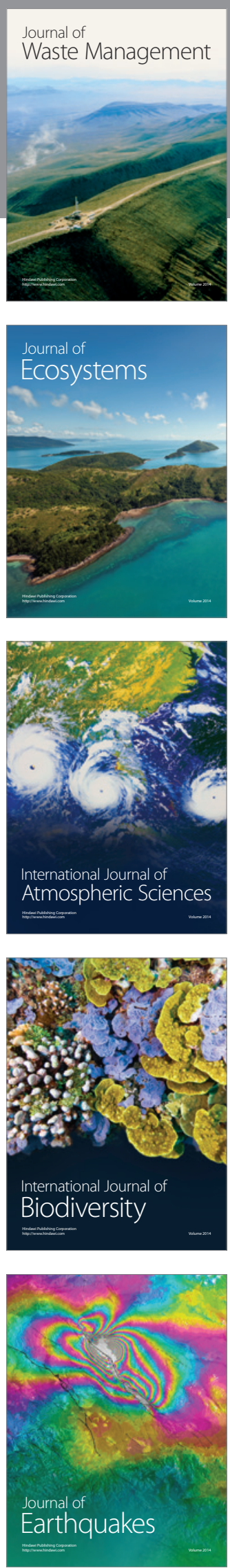
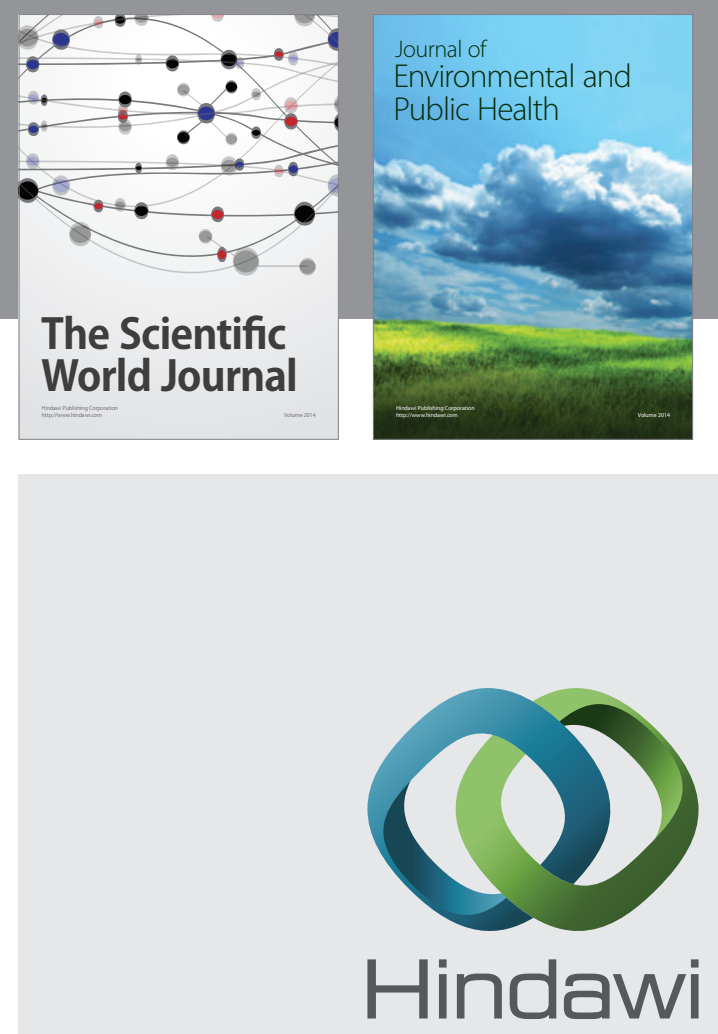

Submit your manuscripts at

http://www.hindawi.com
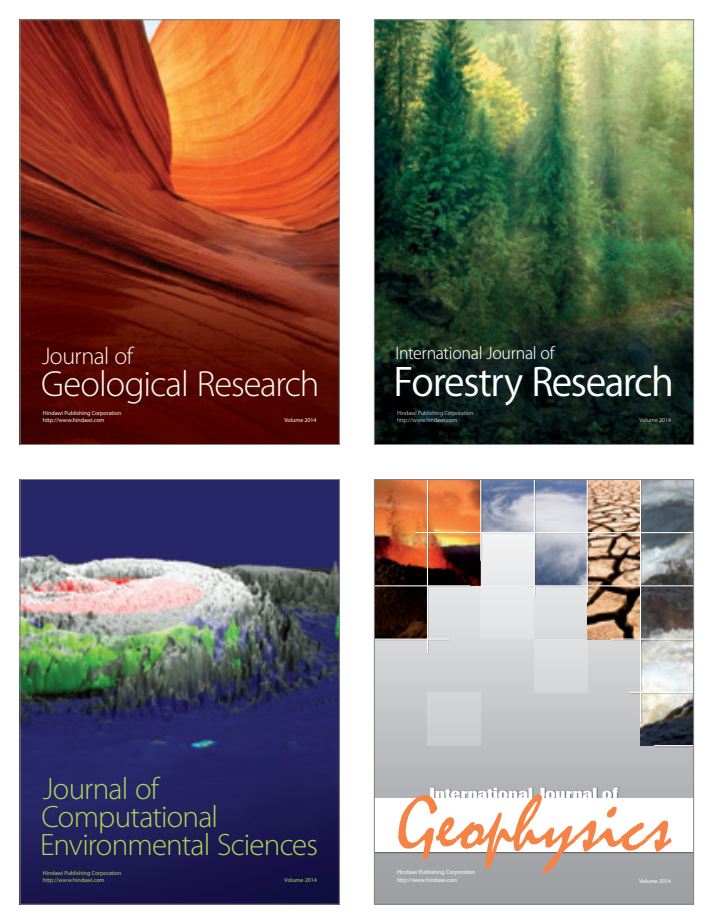
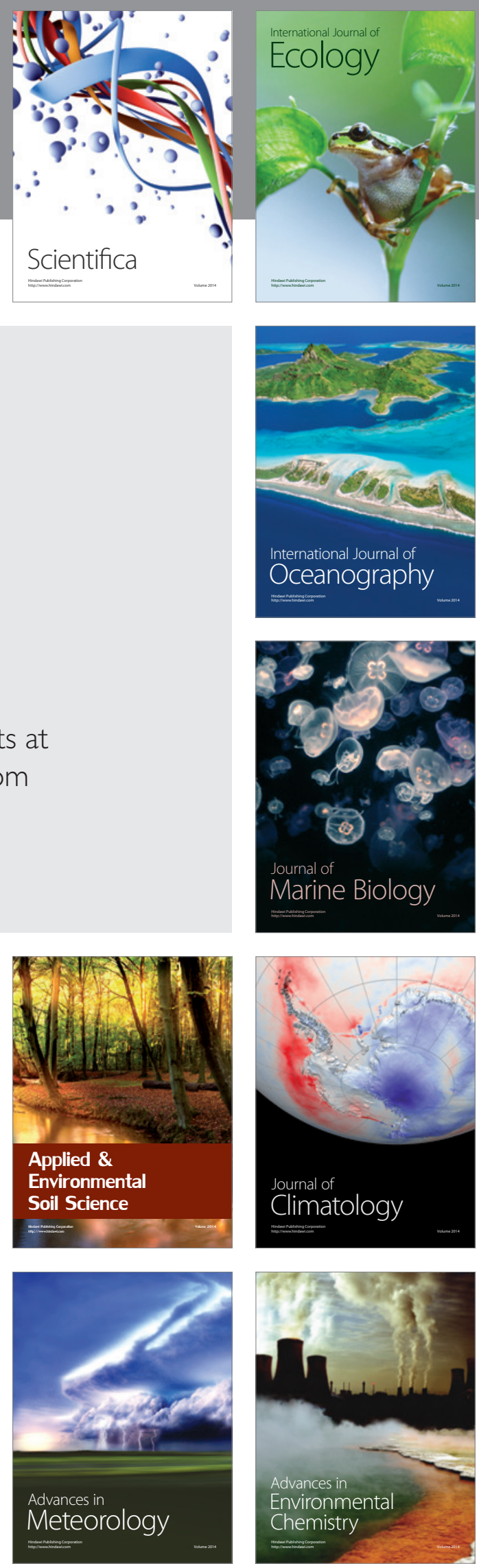